\title{
Cytokines and cervical length: a pilot study of relationship to incidence of preterm birth
}

\author{
Monica Smith ${ }^{1+}$, Dara Seybold ${ }^{2+}$, Kenny P Aladefa ${ }^{2+}$, Jamie L Miller ${ }^{3+}$ and Byron C Calhoun ${ }^{1+*}$ \\ *Correspondence: Byron.calhoun@camc.org \\ ${ }^{\dagger}$ All authors contributed equally to this work. \\ 'Department of Obstetrics and Gynecology, West Virginia University Physicians of Charleston, Charleston, West Virginia, United \\ States. \\ ${ }^{2}$ Center for Health Services \& Outcomes Research, Charleston Area Medical Center Health Education and Research Institute, \\ Charleston West Virginia, United States. \\ ${ }^{3}$ Life Science Division, Mid-Atlantic Technology, Research \& Innovation Center, Morgantown, West Virginia, United States.
}

\begin{abstract}
Objective: To test if levels of interleukins (IL) in a low risk obstetric population coupled with transvaginal cervical length help predict spontaneous pre-term birth.

Materials and methods: Prospective pilot study of 39 patients presenting for initial prenatal care. Vaginal swabs from each patient evaluated for IL-1A, IL-1B, IL-6, IL-8, IL-10 and IL-13 levels via ELISA kits. Mean cytokine levels compared between preterm/term birth groups with Student t-test. Cytokine levels tested to evaluate correlation with shorter cervical lengths using Pearson's correlation.

Results: Of the 39 patients enrolled, 8 (20.5\%) delivered pre-term. Mean IL-1A, IL-4, IL-10 and 11-13 levels were not statistically different between pre-term and term births. However, IL-1B and IL-6 levels were significantly lower in preterm birth group $(6.28 \mathrm{pq} / \mathrm{ml} \pm 12.7$ and $3.96 \mathrm{pg} / \mathrm{ml} \pm 3.8)$ compared to term births $(25.41 \mathrm{pq} / \mathrm{ml} \pm 41.6 ; \mathrm{p}=0.035 \mathrm{and} 35.7 \mathrm{pq} / \mathrm{ml}$ $\pm 55.3 ; \mathrm{p}=0.003$ ). There was moderate correlation between IL-10 and cervical length ( $r=0.54 ; \mathrm{p}=0.002)$. IL-1A, IL-1B, IL-6, IL10 and IL-13 had no correlation with cervical length.

Conclusions: Unlike previous reports, IL-1B and IL-6 levels were lower in our preterm birth patients. IL-10 may provide a moderating effect on both inflammatory cytokines and affect cervical length by its anti-inflammatory action. Further study with larger numbers of patients is warranted.
\end{abstract}

Keywords: Cervical length, cytokines, preterm birth, interleukins, pearson's correlation

\section{Introduction}

Amniotic and chorionic phospholipase $\mathrm{A}_{2}$ activity precipitates term labor. Numerous investigators have suggested that normal labor is triggered by activation of phospholipase $A_{2}$, which produces an increase in free arachidonic acid and increase in the synthesis of prostaglandins by hydrolyzing the phospholipids in the placental membranes [1].

Phospholipase $\mathrm{A}_{2}$ activities are higher in microorganisms that cause urinary tract infections, bacteria vaginosis, and neonatal sepsis, in comparison to that of membrane phospholipase activities. There is a strong association between premature labor and intrauterine infection, urinary tract infection and early neonatal sepsis. The cytokines represent a family of immunologic products that have significant effects on reproduction. A few relevant inflammatory cytokines are interleukin (IL)-1, IL-6, and tumor necrosing factor-alpha (TNF-alpha). So me of the regulatory cytokines are IL-4, IL-10, and IL-13.

Further, the modulating cytokines of interleukin (IL)-4, IL-10, and IL-13 decrease the inflammatory response by IL-6, IL-8, and TNF-alpha [6]. Recent information by [6], on the receptor activity of IL-4, IL-10, and IL-13, notes that these anti-inflammatory cytokines may be involved in the maternal response to infection. Specifically, the authors found that African-American women had a decrease in the production of IL-10 in the face of bacterial vaginosis which may partially explain African-American women's increased risk for preterm delivery as a result of infectious processes. Microorganisms may augment premature labor with phospholipase $\mathrm{A}_{2}$ activity from endocervical and/or intrauterine contamination or infection, producing deacylation of arachidonic acid from amniotic phospholipids with increased concentrations of free arachidonic acid and increased prostaglandin synthesis, which triggers labor [1].

Age at gestation and cervical length measurement are also linked to preterm birth due to the shortening of the cervix space by the colonizing phospholipase producing bacteria and reduction in a normal vaginal flora that may correlate to the number of life sexual partners. Teenagers with limited sexual exposures may have less normal vaginal flora than an adult with numerous life sexual partners. All of the above factors may compound the occurrence of preterm birth. Rates of preterm birth have continued to increase despite intensive research efforts over the last several decades. A woman who has a 
Smith et al. Immunology Innovation 2013,

http://www.hoajonline.com/journals/pdf/2053-213X-1-2.pdf

doi: $10.7243 / 2053-213 \mathrm{X}-1-2$

spontaneous preterm birth is at high risk for a subsequent preterm birth [8]. Studies have identified clinical, sonographic, and biochemical markers that help to identify the women at highest risk [4]. Determining cervical length, routine culturing of cervical microorganisms, and determination of cytokines could identify and potentially prevent preterm birth. Effective interventions to prevent preterm birth, however, remain elusive.

\section{Methods and materials}

We conducted a prospective pilot study of 50 obstetric patients. Our inclusion criteria consisted of: gestational age $<34$ weeks, singleton gestation, urinalysis and urine culture collected via clean catch, maternal age range $14-45$ years, patient receiving prenatal care at CAMC Women's Medicine Center. Patients were excluded for the following reasons: women in labor or with uterine contractions, known fetal anomaly, cervical cerclage, multiple gestations, prior history of excisional cervical biopsy eg., cold knife cone, loop electrosurgical excision procedure, laser conization, mullerian anomaly, patients with two or more D\&C secondary to spontaneous or induced abortion.

For study consented patients, the following were performed in addition to standard prenatal care at the initial prenatal visit: transvaginal ultrasonograph cervical length measurements between 12 0/7 and 31 6/7 weeks of gestation, cervical cultures for standard microbiological analysis (including bacteria vaginosis, gonorrhea and chlamydia), as well as the collection of additional vaginal fluid for cytokines (IL-1A, IL-1B, IL-4, IL-6, IL-10 and IL-13) and both serum and vaginal phospholipase $A_{2}\left(P L A_{2}\right)$ samples for analysis.

Vaginal swab samples were placed individually into $250 \mathrm{~mL}$ Tris and frozen while awaiting analysis. Peripheral venous blood samples were collected into BD Vacutainer ACD tubes by trained personnel using standard phlebotomy techniques. Buffy coat (white blood cells) were isolated from the blood sample via centrifugation at room temperature for 10 minutes at $3300 \times$ g, no brake. Red blood cells were lysed by conventional hypotonic lysis with the resulting white cell pellet resuspended in $1 \mathrm{~mL} 1 \mathrm{x}$ PBS.

Vaginal swab samples were briefly vortexed upon thawing One $\mathrm{mL}$ of vaginal sample solution sample was removed for sonication in parallel to harvested white blood cells from peripheral blood sample. Sonication was performed using Sonicator ${ }^{\circledast}$ Ultrasonic Processor XL by Misonix ${ }^{\circledast}$ Incorporated (Farmingdale, NY), 30\% for 90 seconds, repeated for a total of two times per sample.

Protein concentration samples were determined using commercially available Pierce BCA Protein Assay Kit according to product insert with endpoint sample reading at $562 \mathrm{~nm}$ absorbance on BioTek ${ }^{\circledast}$ Instruments, Inc, $\mu$ Quant Spectrophotometer Reader with KCJunior ${ }^{\mathrm{TM}}$ Software (Winooski, VT). sPLA, levels were determined in both vaginal swab and peripheral blood samples using commercially available Assay Designs Correlate-Enzyme Assay secretory Phospholipase $\mathrm{A}_{2}$ kit (Ann Arbor, MI) according to kit instructions. Prepared samples were read at $405 \mathrm{~nm}$ on BioTek ${ }^{\circledR}$ Instruments, Inc, $\mu$ Quant Spectrophotometer Reader with KCJunior ${ }^{\mathrm{TM}}$ Software (Winooski, VT). Samples were analyzed in duplicate and are expressed as the mean value.

Cytokine levels were determined from collected vaginal swab samples by thawing and briefly vortexing sample. Human IL-4, IL-6, IL-10, IL-13 levels were determined using commercially available Invitrogen Ultrasensitive Immunoassay kits. Human IL-1 A was tested using commercially available Invitrogen Immunoassay Kit and human IL-1B was analyzed using commercially available Amersham Interleukin-1 Beta BioTrak ELISA System. All testing was done according to product insert instructions with IL-4, $-6,-10$, and -13 using samples diluted 1:100 in kit included standard diluents buffer and IL-1A and IL-1B using non-diluted samples. Samples were read at 450 $\mathrm{nm}$ on BioTek ${ }^{\otimes}$ Instruments, Inc, $\mu$ Quant Spectrophotometer Reader with KCJunior ${ }^{\mathrm{TM}}$ Software (Winooski, VT). Samples were analyzed in duplicate and are expressed as the mean value.

Descriptive statistics and univariate analysis were used as appropriate for continuous or categorical variables. Continuous variables were presented as means and standard deviations and were compared by using the Student t-test. Categorical variables were reported as percentages and were compared using chi-square and if necessary, Fisher's exact test. Logistic regression analysis were used to control for potential confounders. An alpha of 0.05 was used as the determination of statistical significance.

\section{Results}

Findings were analyzed in 39 patients ( 11 of the 50 did not have birth data available). Of the 39 women who met the inclusion criteria, several patient demographic characteristics were considered. (See Table 1) Of these patients enrolled, 8 (20.5\%) delivered pre-term. Infection was associated with spontaneous pre-term birth, infection rate at $75 \%(6 / 8)$ versus $33 \%$ (10/31) for term birth $(\mathrm{p}=0.045)$. No patients had shortened cervixes $<30 \mathrm{~mm}$, while $9.68 \%$ had measurements $<35 \mathrm{~mm}$. Mean IL-1A, IL-4, IL-10 and IL-13 levels were not statistically different between pre-term and term births as indicated in Figure 1. However, IL-1B and IL-6 levels were significantly lower in preterm birth group $(6.28 \mathrm{pq} / \mathrm{ml} \pm 12.7$ and $3.96 \mathrm{pg} / \mathrm{ml} \pm 3.8)$ compared to term births $(25.41 \mathrm{pq} / \mathrm{ml} \pm 41.6 ; \mathrm{p}=0.035$ and $35.7 \mathrm{pq} / \mathrm{ml} \pm 55.3 ; \mathrm{p}=0.003)$. There was moderate correlation between IL-10 and cervical length $(r=0.54 ; p=0.002)$. IL-1A, IL-1B, IL-6, IL-4 and IL-13 had no correlation with cervical length. Cytokine concentrations were not associated with infection. (See Table 2).

\section{Discussion}

This pilot study is the first to attempt to prospectively evaluate the production of cytokines with relationship to cervical length and preterm birth. Unlike [5], we did not find elevated levels of IL- 6 consistent with the finding of occult intramniotic infection as a precursor to preterm labor. Our findings of lower IL-B and 
Smith et al. Immunology Innovation 2013,

http://www.hoajonline.com/journals/pdf/2053-213X-1-2.pdf

Table 1. Patient characteristics.

\begin{tabular}{|c|c|c|c|c|}
\hline $\begin{array}{l}\text { Patient } \\
\text { Characteristics }\end{array}$ & $\begin{array}{l}\text { Total }(n=39) \\
N(\%) \text { or mean }(S D)\end{array}$ & $\begin{array}{l}\text { SPB }(n=8) \\
N(\%) \text { or mean }(S D)\end{array}$ & $\begin{array}{l}\text { No SPB }(n=31) \\
N(\%) \text { or mean }(S D)\end{array}$ & p value \\
\hline Maternal age (years) & $24.0(6.3)$ & $25.1(5.5)$ & $23.7(6.5)$ & 0.576 \\
\hline Teen $(<20$ years $)$ & $8(20.5 \%)$ & $0(0.0 \%)$ & $8(25.8 \%)$ & 0.128 \\
\hline Adult (20-41 years) & $31(79.5 \%)$ & $8(100.0 \%)$ & $23(74.2 \%)$ & - \\
\hline Ethnicity & - & - & - & 0.110 \\
\hline European American & $36(92.3 \%)$ & $7(87.5 \%)$ & $29(93.5 \%)$ & - \\
\hline African American & $2(5.1 \%)$ & $0(0.0 \%)$ & $2(6.5 \%)$ & - \\
\hline Asian American & $1(2.6 \%)$ & $1(12.5 \%)$ & $0(0.0 \%)$ & - \\
\hline Nulliparity & $19(48.7 \%)$ & $5(62.5 \%)$ & $14(45.2 \%)$ & 0.317 \\
\hline $\begin{array}{l}\text { Gestational Age } \\
\text { (weeks) }\end{array}$ & $10.8(4.8)$ & $10.6(5.3)$ & $10.8(4.8)$ & 0.912 \\
\hline Hx preterm birth & $5(12.8 \%)$ & $2(25.0 \%)$ & $3(9.7 \%)$ & 0.268 \\
\hline $\begin{array}{l}\text { Adequate Prenatal } \\
\text { Care }\end{array}$ & $10(25.6 \%)$ & $2(25.0 \%)$ & $8(25.8 \%)$ & 0.671 \\
\hline Tobacco Use & $23(59.0 \%)$ & $5(62.5 \%)$ & $18(58.1 \%)$ & 0.575 \\
\hline $\begin{array}{l}\text { Drug Use (All TCH, } \\
1 \text { Opiate, } 1 \text { Cocaine) }\end{array}$ & $8(20.5 \%)$ & $3(38 \%)$ & $5(16 \%)$ & 0.323 \\
\hline Infection & $16(41.0 \%)$ & $6(75 \%)$ & $10(33 \%)$ & 0.045 \\
\hline HTN & $3(7.7 \%)$ & $1(12.5 \%)$ & $2(6.5 \%)$ & 0.508 \\
\hline $\mathrm{DM}$ & $5(12.8 \%)$ & $2(25 \%)$ & $3(9.7 \%)$ & 0.268 \\
\hline- & - & $\mathrm{n}=7$ & $\mathrm{n}=24$ & - \\
\hline Cervical Length & $4.2(0.9)$ & $3.8(0.5)$ & $4.3(1.0)$ & 0.214 \\
\hline
\end{tabular}

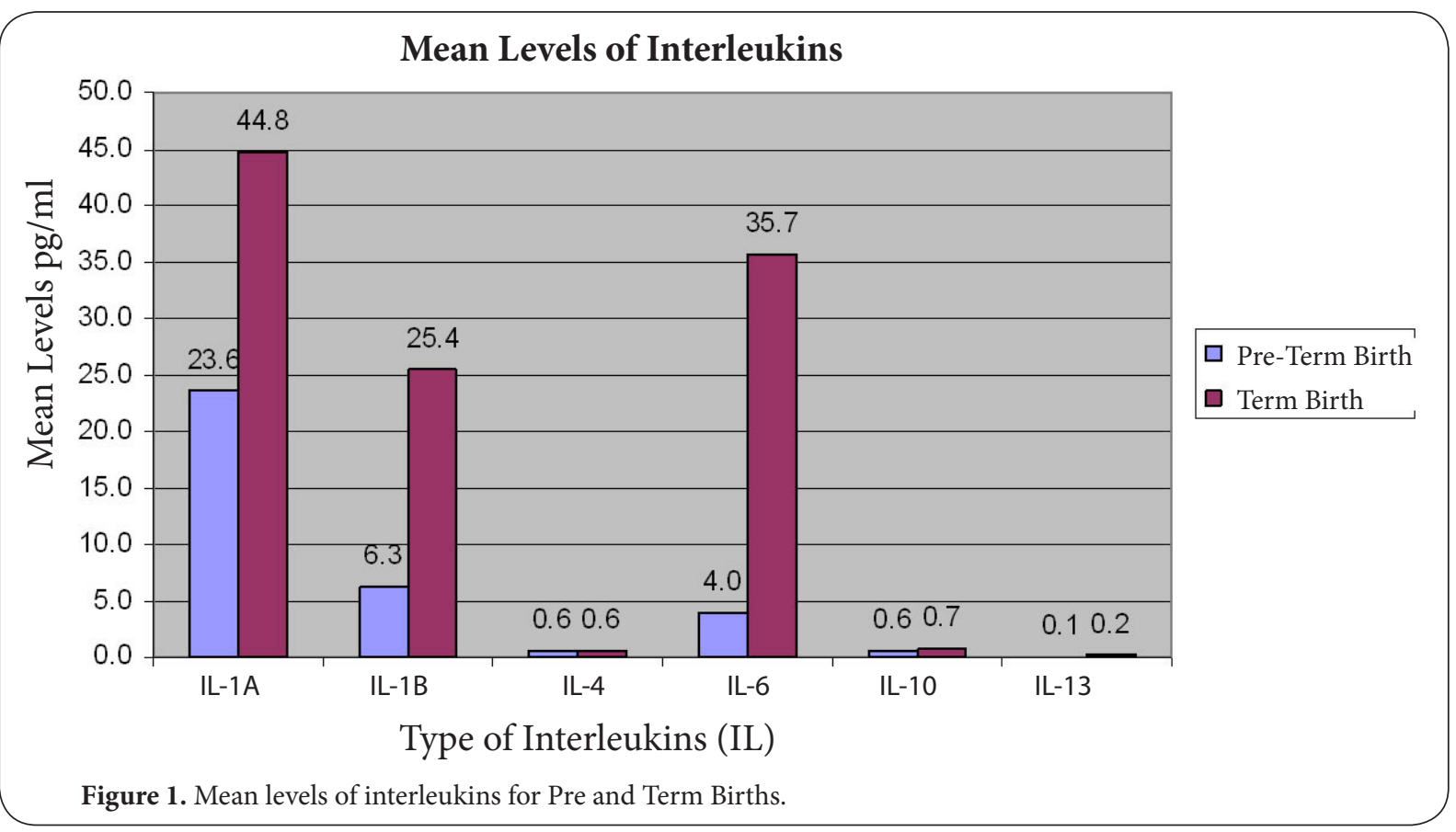

IL-6 levels in the preterm birth patients are consistent with [3], who found that low levels of IL-A, IL-B, and IL- 6 all were related to preterm birth [3]. The findings of [7] also found lower levels of IL-B and IL-6 in patients who delivered prior to 34 weeks [7]. We also did not note any correlation with the inflammatory cytokines of IL-1A, IL-1B, and IL-13 with preterm 
Smith et al. Immunology Innovation 2013,

http://www.hoajonline.com/journals/pdf/2053-213X-1-2.pdf

Table 2. Interleukin Levels by Pre and Term Births.

\begin{tabular}{llll}
\hline Variables & $\begin{array}{l}\text { SPB }(\mathbf{n}=\mathbf{8}) \\
\mathbf{N}(\%) \text { or mean }(\mathrm{SD})\end{array}$ & $\begin{array}{l}\text { No SPB }(\mathbf{n}=\mathbf{3 1}) \\
\mathbf{N}(\%) \text { or mean }(\mathrm{SD})\end{array}$ & P value \\
\hline IL-1A & $23.6(34.3)$ & 44.8 & 0.373 \\
IL-1B & $\mathbf{6 . 2 8 ( 1 2 . 7 )}$ & $\mathbf{2 5 . 4 1 ( 4 1 . 6 )}$ & $\mathbf{0 . 0 3 5}$ \\
IL-4 & $0.62(0.8)$ & $0.59(0.8)$ & 0.943 \\
IL-6 & $\mathbf{3 . 9 6 ( 3 . 8 )}$ & $\mathbf{3 5 . 7 0}(55.3)$ & $\mathbf{0 . 0 0 3}$ \\
IL-10 & $0.62(0.8)$ & $0.67(1.3)$ & 0.918 \\
IL-13 & $0.10(0.1)$ & $0.16(0.2)$ & 0.167 \\
\hline
\end{tabular}

birth. We did find a moderate correlation between IL-10 and cervical length $(r=0.54 ; p=0.002)$. This is entirely consistent the concept of IL-10 as a mediator of inflammatory response. IL-1 A, IL-1B, IL-6, IL-4 and IL-13 had no correlation with cervical length in our study. This is in contrast to the study by [2] which found a significant correlation with IL-6 and cervical length as a predictor of preterm birth [2].

\section{Competing interests}

The author declare no competing interests.

\section{Acknowledgement}

Support provided by Charleston Area Medical Center Foundation.

\section{Publication history}

Editor: Robert L. Elliott, Elliott Baucom Head Breast

Cancer Research and Treatment Center, USA.

Received: 28-Jun-2013 Accepted: 15-Jul-2013

Published: 26-Jul-2013

\section{References}

1. Bejar R, Curbelo V, Davis C and Gluck L. Premature labor. II. Bacterial sources of phospholipase. Obstet Gynecol. 1981; 57:479-82. | PubMed

2. Brik $M$, Antonio P, Perales-Puchalt $A$, Diago $V$ and Perales $A$. Cervical interleukin- 6 as a predictive test for preterm delivery in symptomatic women: preliminary results. Eur J Obstet Gynecol Reprod Biol. 2011; 155:14-8. | Article | PubMed

3. Kalinka J, Sobala W, Wasiela M and Brzezinska-Blaszczyk E. Decreased proinflammatory cytokines in cervicovaginal fluid, as measured in midgestation, are associated with preterm delivery. Am J Reprod Immunol. 2005; 54:70-6. | Article | PubMed

4. Owen J, Yost N, Berghella V, Thom E, Swain M, Dildy GA, 3rd, Miodovnik $M$, Langer $\mathrm{O}$, Sibai B and McNellis D. Mid-trimester endovaginal sonography in women at high risk for spontaneous preterm birth. JAMA. 2001; 286:1340-8. | Article | PubMed

5. Romero R, Yoon BH, Mazor M, Gomez R, Diamond MP, Kenney JS, Ramirez M, Fidel PL, Sorokin Y, Cotton D and et al. The diagnostic and prognostic value of amniotic fluid white blood cell count, glucose, interleukin-6, and gram stain in patients with preterm labor and intact membranes. Am J Obstet Gynecol. 1993; 169:805-16. | Article | PubMed

6. Simhan HN, Ryckman KK, Williams SM and Krohn MA. Genetic regulation of cervical antiinflammatory cytokine concentrations during pregnancy. Am J Obstet Gynecol. 2008; 199:163 e1-163 e11. | Article | PubMed

7. Simhan $\mathrm{HN}$ and Krohn MA. First-trimester cervical inflammatory milieu and subsequent early preterm birth. Am J Obstet Gynecol. 2009; 200:377 e1-4. | Article | PubMed

8. Spong $\mathrm{CY}$. Prediction and prevention of recurrent spontaneous preterm birth. Obstet Gynecol. 2007; 110:405-15. | Article | PubMed

\section{Citation:}

Smith M, Seybold D, Aladefa K P, Miller J L and Calhoun B C. Cytokines and cervical length: a pilot study of relationship to incidence of preterm birth. Immunol Innov. 2013; 1:2. http://dx.doi.org/10.7243/2053-213X-1-2 